\title{
MODELLING EFFECTIVE THERMAL CONDUCTIVITY COEFICIENT OF SALIX VIMINALIS L. DRIED PIECES
}

\author{
Karolina Slomka-Polonis ${ }^{1}$, Boguslawa Lapczynska-Kordon ${ }^{1}$, Slawomir Francik ${ }^{1}$, Renata Francik ${ }^{2}$ \\ ${ }^{1}$ University of Agriculture in Krakow, Poland; ${ }^{2}$ Jagiellonian University, Poland \\ karolina.slomka-polonis@urk.edu.pl,boguslawa.lapczynska-kordon@urk.edu.pl, \\ slawomir.francik@urk.edu.pl,renata.francik@uj.edu.pl
}

\begin{abstract}
The effective thermal conductivity coefficient $\left(\lambda_{\mathrm{ef}}\right)$ of willow Salix Viminalis L. dried pieces was studied by drying the willow at various temperatures. The willow was acquired from the energy crop plantation of the University of Agriculture in Krakow. The dried pieces of willow were covered with insulating coating and then heated in thermal chamber with constant drying agent (air) velocity under various conditions of drying air temperature: $313.15-343.15 \mathrm{~K}\left(40-70{ }^{\circ} \mathrm{C}\right)$. The experiment set up caused the longitudinal direction of the heat flow. Single piece of willow was heated in 15 minutes period. With the use of two thermocouples the temperature of single sample was measured in the two points: on the surface and at half-height in the middle. The specific density and porosity of the willow particles were measured with AccuPyc II 1340 and GeoPyc 1360 pycnometers. On basis of the Fourier equation of heat transfer and concept of reverse problem formulation the thermal conductivity coefficient $(\lambda)$ was calculated. The effective thermal conductivity coefficient $\left(\lambda_{\mathrm{ef}}\right)$ was determined using a general model, in which porosity and density of the willow pieces were covered. The effect of the drying agent temperature on the $\left(\lambda_{\mathrm{ef}}\right)$ coefficient was investigated. The rise in the air temperature led to an increase in the $\left(\lambda_{\mathrm{ef}}\right)$ coefficient rate in the experiments. At the 15th minute the $\left(\lambda_{\mathrm{ef}}\right)$ coefficient varied from 0.038 $\left(\mathrm{W} \cdot \mathrm{m}^{-1} \cdot \mathrm{K}^{-1}\right)$ at $313.15 \mathrm{~K}\left(40{ }^{\circ} \mathrm{C}\right)$ temperature and $0.086\left(\mathrm{~W} \cdot \mathrm{m}^{-1} \cdot \mathrm{K}^{-1}\right)$ at $343.15 \mathrm{~K}\left(70{ }^{\circ} \mathrm{C}\right)$. The performance of the model was evaluated by comparing the correlation coefficient $\left(\mathrm{R}^{2}\right)$, root mean square error (RMSE), mean absolute percentage error (MAPE) and the chi-square $\left(\chi^{2}\right)$ between the observed and the predicted effective thermal conductivity coefficient $\left(\lambda_{\mathrm{ef}}\right)$ ratios. The calculated statistical parameters varied over the studied temperature range: RMSE was below 0.014, MAPE ranged from 6 to $17 \%, R^{2}$ ranged from 0.91 to $0.97, \chi^{2}$ below 0.019 showed good model adjustment to the experimental data.
\end{abstract}

Keywords: thermal conductivity, thermal diffusivity, thermal properties, biomass, Salix Viminalis L.

\section{Introduction}

Thermo-physical properties, such as thermal conductivity, specific heat and the coefficient of diffusion of heat, are very important in the energy balance calculation, modeling processes and the power systems, heating, cooling as well [1]. Wood is widely used as a building material, but also as a fuel [2]. Therefore, the thermophysical properties are necessary for calculations related to the process of heat transfer during thermal processing of biofuels. Wood is a lignocellulosic material, like other biological materials. These materials are characterized by a porous, multiphase structure and therefore thermo-physical properties mainly depend on the water content, density, porosity and shape, and dimensions of the material as well [3-5].

Cammerer and Achtziger [5] discussed the influence of moisture on the thermal conductivity for several wood species and particle board. They found the thermal conductivity to increase by $1-2 \%$ per percent increase of the moisture content for solid wood and 1-2.4\% for particle boards.

The heat transfer process in wood material under steady state was often determined by the thermal conductivity in different measurement settings. The hot plate apparatus involves specific requirements on the experimental material. It has to be isotropic, homogeneous and dry or nearly dry [1;5-7]. It was also necessary to obtain the best conditions for testing samples and the heater-cooler surface attachment. Because the measurements were time consuming, the alternative approach was applied, i.e. hot wire, hot strip or transient flat source - with a much shorter measurement time, important for moist materials [7; 8]. However, the determination of the heat flux emitted by the source and thermal resistance between the specimen and the heater are difficult to estimate [9].

Wood is an anisotropic material; moreover, the heat transport process is carried out in transient conditions. Therefore, in many works the reverse problem formulation, often computer-assisted, has been applied $[10 ; 11]$. Attempts were also made to generalize the model of changes in the thermal conductivity coefficient depending on the water content, temperature and density of the testing samples [12]. Such models allow to predict the changes of this size from the parameter changes, and this is of great importance in modeling of complex thermal and energy systems. 
Therefore, the aim of the work was to develop a model describing changes in the thermal conductivity coefficient of energy willow pieces depending on the temperature and porosity of the material.

\section{Materials and methods}

The research made use of the energy-crop willow Salix Viminalis L. (hemp willow) in the form of pieces. The willow comes from an energy plantation of the University of Agriculture in Kraków, from a crop in 2015-2016. Only straight willow shoots, with undamaged bark on $1 \mathrm{~m}$ length were collected for the experiment. The shoots of willow were prepared with the use of a circular cutter into cylinder shape pieces with the diameter size $D$ compared to its length $L(D \sim L)$ (Fig. 1A). Each piece was then drilled with a $3 \mathrm{~mm}$ diameter drill to a depth of half of the diameter $(1 / 2 D)$ at half height $(1 / 2 L)$.

To determine the thermophysical parameters of solid, the willow samples were dried in the $378.15 \mathrm{~K}\left(105^{\circ} \mathrm{C}\right)$ for $48 \mathrm{~h}$ until the equilibrium moisture content was reached. After that the test samples were weighed $\left(m_{1}\right)$ on a RADWAG Max 50/1 laboratory scale with accuracy of $0.1 \mathrm{mg}$.

The side walls and bottom parts of the samples were insulated with the heat-insulating mat consisting of $0.05 \mathrm{~mm}$ aluminium foil laminated onto $4 \mathrm{~mm}$ polystyrene layer (Fig. 1B). The main focus of the mentioned above sample preparation was to enable the heat transfer strictly by the top surface of the sample.

a)

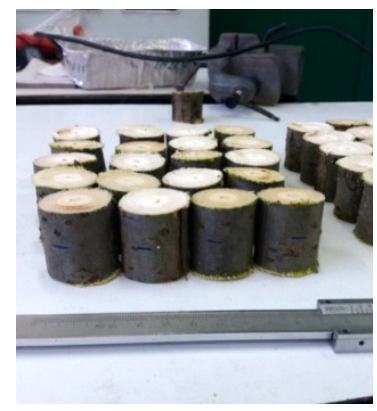

b)

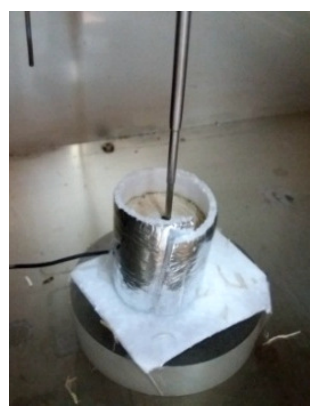

Fig. 1. Energy-crop willow Salix Viminalis L. pieces (a), experimental setup of examined samples of willow (b)

Experiments were carried out in a laboratory dryer Pol-Eko SLW-32, where the insulated wood pieces were fixed individually. The heating experiments were performed at $313.15,323.15,333.15$ and $343.15 \mathrm{~K}\left(40,50,60\right.$ and $\left.70{ }^{\circ} \mathrm{C}\right)$ air temperatures, the air velocity was kept constant. In the course of the experiment, every 3 minutes the temperature of the samples was measured in two places: on the sample surface $\left(T_{1}\right)$ and at half height in the middle of the sample $\left(T_{2}\right)$ (Fig. 2). Temperature was measured with the use of two thermocouples TM-1300 K with accuracy of up to $0.1{ }^{\circ} \mathrm{C}$. Each sample was weighed after heating $\left(m_{2}\right)$ with the use of the RADWAG Max 50/1 balance with accuracy of $0.1 \mathrm{mg}$. The heating time for each sample amounted to 15 minutes.

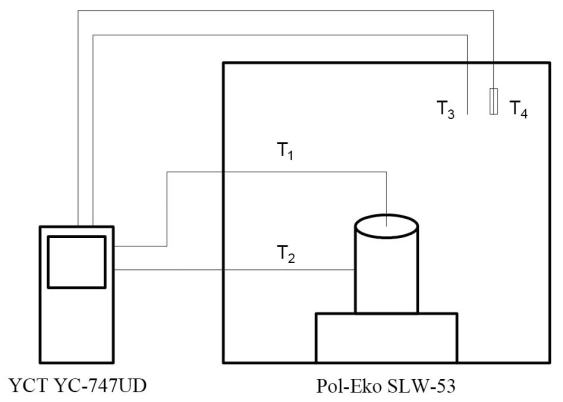

Fig. 2. Schematic diagram of experimental equipment

Heating was performed in five repetitions for each range of temperature of the willow samples. For the needs of the experiment, there were two extra thermocouples installed in the heating chamber to measure the dry-bulb $\left(T_{3}\right)$ and wet-bulb $\left(T_{4}\right)$ temperature and thus the relative humidity in the drying chamber was calculated. 
In order to describe the mathematical model of the heat transport on the edge of the area and inside the sample during the measurement experiment, the following assumptions were made:

- sample is a porous, isotropic material.

- sample has the shape of a cylinder.

- heat exchange occurs only through the upper base of the cylindrical sample (the side of the cylindrical sample and the bottom were insulated during the experiment).

- heat flow delivered by the surface of the upper base of the sample is constant because the measurement of the heating of the sample was carried out under isothermal conditions.

- density, specific heat and effective thermal conductivity are constant during the measurement.

- heat transport takes place in steady-state conditions, only along the sample height in the sample axis.

Taking into account the described above assumptions, the phenomenon of heat exchange in analysed material was described by the mathematical one-dimensional heat flow model for steady state, based on the Fourier law (1):

$$
\dot{q}=-\lambda \frac{d T}{d x},
$$

where $\dot{q}$-heat-flow density, $\mathrm{W} \cdot \mathrm{m}^{-2}$;

$\lambda$ - thermal conductivity, $\mathrm{W} \cdot \mathrm{m}^{-1} \cdot \mathrm{K}^{-1}$;

$T$ - temperature, $\mathrm{K}$;

$x$ - Cartesian coordinate, $\mathrm{m}^{-1}$.

After integrating the equation (1) with the following boundary conditions: for $z_{c . s .}=s, T=T_{1}$ and $z_{\text {s.s. }}=0$, and $T=T_{2}$, where the indices "c.s." and "s.s" stand for the geometric centre axis of the sample and centre of the surface area of the sample base, the density of the heat-flow $\dot{q}$ determines the relationship (2):

$$
q=-\frac{\lambda}{s}\left(T_{2}-T_{1}\right)
$$

Effective thermal conductivity $\left(\lambda_{e f}\right)$ was set in an indirect way using the inverse problem method. After the temperature field $\left(T_{1}, T_{2}\right)$ is obtained, then by transforming formula (2) the formula was received for effective thermal conductivity $\left(\lambda_{e f}\right)(3)$ :

$$
\lambda_{e f}=\frac{s}{\left(T_{2}-T_{1}\right)} \dot{q}
$$

where $\lambda_{e f}$ - effective thermal conductivity of the willow sample, $\mathrm{W} \cdot \mathrm{m}^{-1} \cdot \mathrm{K}^{-1}$;

$\dot{q}$ - heat-flow density, $\mathrm{W} \cdot \mathrm{m}^{-2}$;

$T_{1}, T_{2}$ - temperatures on the surface and in the geometric centre of the sample axis $\left(T_{1}<T_{2}\right), \mathrm{K}$;

$\mathrm{s}-$ length path of heat conductivity, $\mathrm{m}$.

In practice, $s$ is the distance between thermocouples that measure temperatures $T_{1}, T_{2}$, then under considering conditions $s=1 / 2 L$.

The heat-flow transfer into the sample causes the change of its unit internal energy with the time, $\tau$. The dried piece of the willow is a typical porous material with partially open-cell structure. It consists of the gas phase and solid phase, so the heat-flow density $\dot{q}$ could be expressed as a sum of the unit change of the internal energy of the solid phase (willow), and the unit change of the internal energy of the gas phase (air), after the time (4):

$$
\dot{q}=\frac{\Delta u_{s}+\Delta u_{\text {air }}}{\tau}=\frac{c_{p_{-} s}\left(T_{\text {end }}-T_{\text {in }}\right)+c_{p_{-} \text {air }}\left(T_{\text {end }}-T_{\text {in }}\right)}{\tau},
$$

where: $m_{s}$ - mass of the willow piece, $\mathrm{kg}$;

$c_{p_{-} s}-$ specific isobaric heat of the willow piece, $\mathrm{J} \cdot \mathrm{kg}^{-1} \cdot \mathrm{K}^{-1}$; 
$m_{\text {air }}$ - mass of the air in the willow piece, $\mathrm{kg}$;

$c_{p_{-} \text {air }}$ - specific isobaric heat of the air, $\mathrm{J} \cdot \mathrm{kg}^{-1} \cdot \mathrm{K}^{-1}$;

$T_{i n}, T_{\text {end }}$ - initial and final temperature of the heating process in the geometric center of the sample axis, K;

$\Delta u_{s}, \Delta u_{\text {air }}-$ unit internal energy of the willow and of the air, $\mathrm{J} \cdot \mathrm{kg}^{-1}$;

$\tau$ - time, s.

One of the basic properties that can characterize a phase and can be measured directly is density, $\rho, \mathrm{kg} \cdot \mathrm{m}^{-3}$. Considering the volume $\mathrm{V}$ of each phase, the mass of the particular phase is (5):

$$
m_{s}=V_{s} \cdot \rho_{s} i m_{\text {air }}=V_{\text {air }} \cdot \rho_{\text {air }},
$$

where $V_{s}$ - volume of the willow piece, $\mathrm{m}^{3}$;

$\rho_{s}$ - density of the willow piece, $\mathrm{kg} \cdot \mathrm{m}^{-3}$;

$V_{\text {air }}$ - volume of the air in the willow piece, $\mathrm{m}^{3}$;

$\rho_{\text {air }}$ - density of the air, $\mathrm{kg} \cdot \mathrm{m}^{-3}$.

The air volume in porous materials can be achieved by measurement of the willow piece porosity $(\varepsilon)$, which can be formulated as (6):

$$
\varepsilon=1-\frac{V_{s}}{V_{0}}
$$

where $V_{0}-$ total volume of the willow piece, $\mathrm{m}^{3}$.

The air volume in the willow sample can be described as $V_{a i r}=V_{0}-V_{s}$, and then the volume of the willow piece and volume of air can be expressed as (7):

$$
V_{s}=(1-\varepsilon) \cdot V_{0} i V_{\text {air }}=\varepsilon \cdot V_{0},
$$

Considering (5), (7), the total heat-flow can be determined from the following formula (8):

$$
\dot{Q}=\frac{\Delta U}{\tau}=\frac{(1-\varepsilon) \cdot V_{0} \cdot \rho_{s} \cdot c_{s} \cdot\left(T_{\text {end }}-T_{\text {in }}\right)+\varepsilon \cdot V_{0} \cdot \rho_{\text {air }} \cdot c_{\text {air }} \cdot\left(T_{\text {end }}-T_{\text {in }}\right)}{\tau},
$$

Then, the effective thermal conductivity coefficient describes the following relationship (9):

$$
\lambda_{e f}=\frac{s}{\left(T_{2}-T_{1}\right) A} \dot{Q},
$$

where $\mathrm{A}-$ heat transfer surfaces between the sample and the surroundings, $\mathrm{m}^{2}$.

Taking into account the equations (8) and (9), and [13], the effective thermal conductivity coefficient can be calculated from equation (10):

$$
\lambda_{e f}=(1-\varepsilon) \cdot \lambda_{s}+\varepsilon \cdot \lambda_{\text {air }}
$$

where $\lambda_{s}$-thermal conductivity of the willow piece, $\mathrm{W} \cdot \mathrm{m}^{-1} \cdot \mathrm{K}^{-1}$;

$\lambda_{\text {air }}$ - thermal conductivity of the air in the willow piece, $\mathrm{W} \cdot \mathrm{m}^{-1} \cdot \mathrm{K}^{-1}$.

For the measurements of the density of the willow piece $\rho_{s}$ an AccuPyc II $1340 \mathrm{He}$-gas pycnometer was used. The porosity of willow particles was measured with a GeoPyc 1360 quasi-fluid pycnometer. Additional information on the air properties was derived from a physics and chemistry handbook [14].

The specific isobaric heat $\left(c_{p}\right)$ for willow particles was set by means of the experimental method, using the KL 12 calorimeter. It was adopted on the basis of the thermal balance. The specific isobaric heat can be determined by the following formula (9):

$$
c_{p_{-} s}=\frac{\left(m_{c} c_{c}+m_{w} c_{w}\right) \cdot\left(T_{2}-T_{1}\right)}{m_{s}\left(T_{w}-T_{2}\right)},
$$

where $c_{p_{-} s}-$ specific isobaric heat of the willow particle, $\mathrm{kJ} \cdot \mathrm{kg}^{-1} \cdot \mathrm{K}^{-1}$; 
$m_{s}$ - mass of the willow particle, $\mathrm{kg}$;

$m_{c}$ - mass of the calorimeter, $\mathrm{kg}$;

$c_{c}$ - specific isobaric heat of the calorimeter, $\mathrm{kJ} \cdot \mathrm{kg}^{-1} \cdot \mathrm{K}^{-1}$;

$m_{w}$ - mass of the water, $\mathrm{kg}$;

$c_{p_{-} w}$ - specific isobaric heat of the water of $4211.92 \mathrm{~kJ} \cdot \mathrm{kg}^{-1} \cdot \mathrm{K}^{-1}$;

$T_{1}$ - temperature of the water at the beginning and at the end of the measurement respectively, $\mathrm{K}$;

$T_{w}$ - boiling point of the water at given pressure, $\mathrm{K}$.

The experimental data were tested to inspect the goodness of fit of the experimental data with the above calculated model (8). The adjusted coefficient of determination $\left(\mathrm{R}^{2}\right)$, reduced chi-squared $\left(\chi^{2}\right)$, root mean square error (RMSE) and mean absolute percentage error (MAPE) were used to inspect the goodness of fit [15]. The math model is more suitable for higher values of $\mathrm{R}^{2}$ and lower values of $\chi^{2}$, RMSE and MAPE. The following equations were used to calculate the above mentioned parameters $(10,11,12,13)$ :

$$
\begin{gathered}
R M S E=\sqrt{\frac{\sum\left(\lambda_{e f_{-} P}-\lambda_{e f_{-} E}\right)^{2}}{N},} \\
M A P E=\frac{100}{N} \sum\left|\frac{\lambda_{e f_{-} E}-\lambda_{e f_{-} P}}{\lambda_{e f_{-} E}}\right|, \\
R^{2}=1-\left[\frac{\sum\left(\lambda_{e f_{-} P}-\lambda_{e f_{-} E}\right)^{2}}{\sum\left(\lambda_{e f_{-} P}-\overline{\lambda_{e f_{-}}}\right)^{2}}\right], \\
\chi^{2}=\frac{\sum\left(\lambda_{e f_{-} E}-\lambda_{e f_{-} P}\right)^{2}}{N-n},
\end{gathered}
$$

where $\lambda_{\text {ef_P } P}-$ predicted $\lambda_{e f}$ ratio;

$\underline{\lambda_{e f \_}-}-$experimental $\lambda_{\text {ef }}$ ratio;

$\frac{\lambda_{e f_{-} E}}{\lambda_{N_{-}}}$average predicted $\lambda_{e f}$ ratio;

$N$ - number of observations;

$n$ - number of constants in the model.

The calculations and statistical data analysis were performed using R Core Team (2016) software (R Foundation for Statistical Computing, Vienna, Austria. URL https://www.R-project.org/) with the packages: ggpolt, dplyr, stats, agricolae and doBy.

\section{Results and discussion}

Twenty pieces of willow Salix Viminalis L. were used in the presented experiment. The average particle diameter $(D)$ was $0.03138 \mathrm{~m}\left(S D=6.2 \cdot 10^{-4}\right)$, average particle length $(L)$ was $0.0336 \mathrm{~m}$ $\left(S D=6.4 \cdot 10^{-4}\right)$. Initial average mass of the samples $\left(\mathrm{m}_{1}\right)$ was $16.58 \mathrm{~g}(S D=0.2533)$, at the end of the heating process the average mass $\left(m_{2}\right)$ of the particle was $16.58 \mathrm{~g}(S D=0.1513)$. There was not much difference in mass loss in the experiment. The moisture content of the examined material was below $1 \%$. The specific isobaric heat of the willow particle $\left(c_{p_{-} s}\right)$ was $1.7723 \mathrm{KJ} \cdot \mathrm{kg}^{-1} \cdot \mathrm{K}^{-1}$. Relative humidity of the ambient air changed between $80 \%$ at $313.15 \mathrm{~K}\left(40{ }^{\circ} \mathrm{C}\right), 61 \%$ at $323.15 \mathrm{~K}\left(50{ }^{\circ} \mathrm{C}\right), 73 \%$ at $333.15 \mathrm{~K}\left(60{ }^{\circ} \mathrm{C}\right)$ and $69 \%$ at $343.15 \mathrm{~K}\left(70{ }^{\circ} \mathrm{C}\right)$.

It is assumed that the one-dimensional heat transfer in steady-state sample was achieved by the side and bottom edges of the sample insulation. The heat flow was transferred parallel to the specimen axis from the top to the bottom of the specimen. The thermal conductivity of the willow piece $\lambda_{s}$ was calculated from the results of the above mentioned measurement methods. From Figure 4 A it can be seen that the temperature gradient $d T$ between the $T_{1}, T_{2}$ varied depending on the temperature of the heating air (Fig. 4A). It was observed that as the temperature of the heating air increases, the 
temperature gradient increases and the highest value reached at air temperature $T=343.15 \mathrm{~K}\left(70{ }^{\circ} \mathrm{C}\right)$, $d T=283.01 \mathrm{~K}\left(30^{\circ} \mathrm{C}\right)$. At the same time, increasing the temperature gradient influenced the increase of the thermal conductivity coefficient (Fig. 4B).

a)

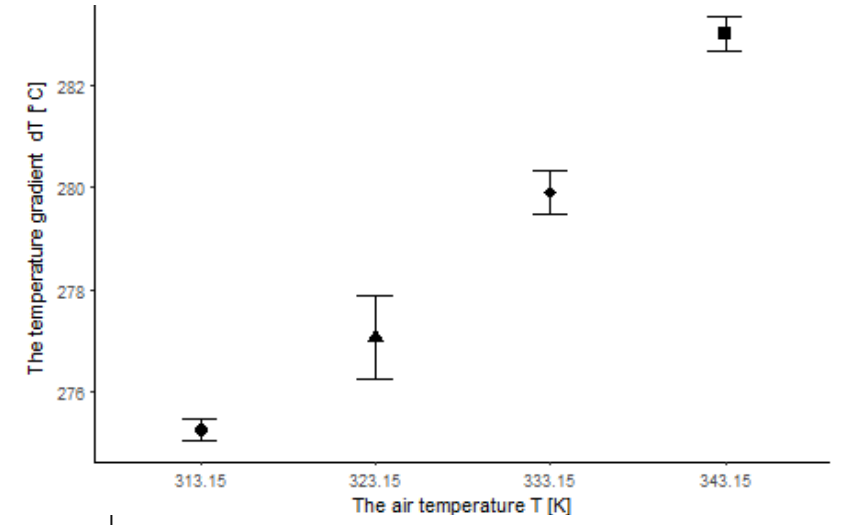

b)

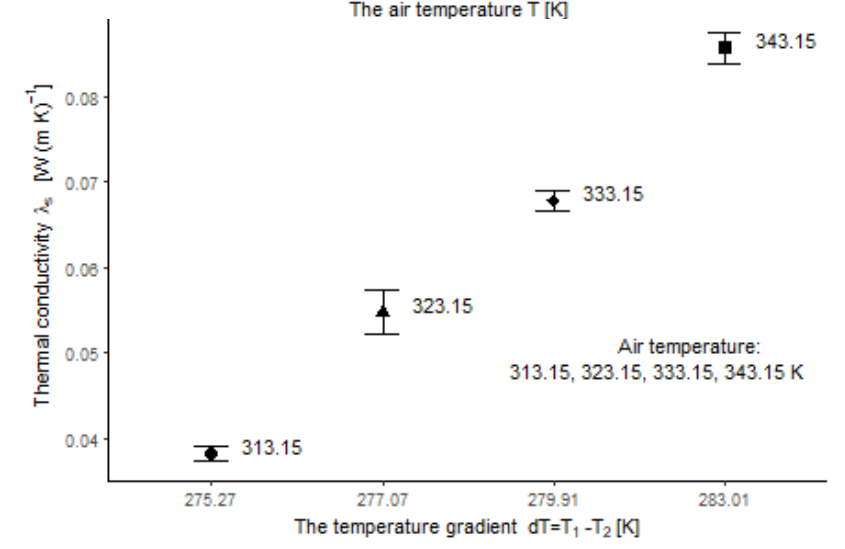

Fig. 4. Influence of air heating temperature on temperature gradient inside samples (a), thermal conductivity of willow piece $\left(\lambda_{\mathrm{s}}\right)$ versus temperature gradient $(b)$

The highest value of the thermal conductivity of the willow piece was measured for the temperature of $343.15 \mathrm{~K}\left(70{ }^{\circ} \mathrm{C}\right), \lambda_{s}=0.0857 \mathrm{~W} \cdot \mathrm{m}^{-1} \cdot \mathrm{K}^{-1}$. It is likely related with the higher temperature gradient $d T$ inside the specimen and evaporation of the water residues from the willow piece. The lowest value of the thermal conductivity of the willow piece was obtained for the temperature of $313.15 \mathrm{~K}\left(40{ }^{\circ} \mathrm{C}\right)$, where $\lambda_{s}=0.0382 \mathrm{~W} \cdot \mathrm{m}^{-1} \cdot \mathrm{K}^{-1}$ (Fig. 4B). The heat transport was performed mainly in the solid phase of the wood, rather than in the gas phase. It should be noted that the thermal conductivity of air $\lambda_{\text {air }}$ is lower compared with the calculated thermal conductivity of dried willow pieces $\lambda_{s}$ (Tab 1).

Table 1

Physical and thermal properties of Salix Viminalis L. pieces*

\begin{tabular}{|c|c|c|c|c|c|}
\hline \multirow{2}{*}{ Parameter } & \multirow{2}{*}{ Unit } & \multicolumn{5}{|c|}{ Temperature, $\mathbf{K}$} \\
\cline { 3 - 6 } & & $\mathbf{3 1 3 . 1 5}$ & $\mathbf{3 2 3 . 1 5}$ & $\mathbf{3 3 3 . 1 5}$ & $\mathbf{3 4 3 . 1 5}$ \\
\hline Total volume $\boldsymbol{V}_{0}$ & $\mathrm{~m}^{3}$ & \multicolumn{5}{|c|}{$2.6466 \cdot 10^{-5}$} \\
\hline Porosity & - & 0.5831 & 0.5587 & 0.5565 & 0.5567 \\
\hline Solid density $\boldsymbol{\rho}_{\boldsymbol{c}}$ & $\mathrm{kg} \cdot \mathrm{m}^{-3}$ & \multicolumn{5}{|c|}{631.7676} \\
\hline Air density $\boldsymbol{\rho}_{\text {air }}$ & $\mathrm{kg} \cdot \mathrm{m}^{-3}$ & 1.092 & 1.057 & 1.025 & 0.996 \\
\hline Air heat capacity $\boldsymbol{c}_{\boldsymbol{p} \text { air }}$ & $\mathrm{kJ} \cdot \mathrm{kg}^{-1} \cdot \mathrm{K}^{-1}$ & 1.014 & 1.016 & 1.017 & 1.018 \\
\hline Solid thermal conductivity $\boldsymbol{\lambda}_{\boldsymbol{c}}$ & $\mathrm{W} \cdot \mathrm{m}^{-1} \cdot \mathrm{K}^{-1}$ & 0.0382 & 0.0547 & 0.0678 & 0.0857 \\
\hline Air thermal conductivity $\lambda_{\text {air }}$ & $\mathrm{W} \cdot \mathrm{m}^{-1} \cdot \mathrm{K}^{-1}$ & 0.0265 & 0.0272 & 0.0279 & 0.0286 \\
\hline $\begin{array}{c}\text { Eff. thermal conductivity, } \\
\text { experimental } \lambda_{\text {eff } \boldsymbol{E}}\end{array}$ & $\mathrm{W} \cdot \mathrm{m}^{-1} \cdot \mathrm{K}^{-1}$ & 0.0276 & 0.0379 & 0.0495 & 0.0671 \\
\hline $\begin{array}{c}\text { Eff. thermal conductivity, modelled } \\
\lambda_{\text {eff } \boldsymbol{P}}\end{array}$ & $\mathrm{W} \cdot \mathrm{m}^{-1} \cdot \mathrm{K}^{-1}$ & 0.0315 & 0.0382 & 0.0449 & 0.0542 \\
\hline
\end{tabular}

* presented results consider 15 th minute of the measurement 
Experimental data were compared with the values predicted by the effective thermal conductivity $\left(\lambda_{\text {eff }}\right)$ model mentioned above. Statistical results show the goodness-of-fit and reveal the high values of $R^{2}$ and low values of $\chi^{2}$ (Table 2). The model represents higher values of the effective thermal conductivity $\left(\lambda_{\text {eff }}\right)$ at lower heating air temperature. The highest values of $R M S E, M A P E, R^{2}$ and $\chi^{2}$ were determined for the temperature $T=318.15$ and $323.15 \mathrm{~K}\left(40\right.$ and $\left.50{ }^{\circ} \mathrm{C}\right)$, where $R^{2}=0.97$ and $M A P E$ are below $7 \%$. At higher heating air temperature the model reveals lower values of $\lambda_{\text {eff. }}$ The worst statistical results were determined at $283.01 \mathrm{~K}\left(70{ }^{\circ} \mathrm{C}\right)$, where $R^{2}=0.92$ and $M A P E=17 \%$. It was caused by the increase of the heat transfer inside the specimen along with the increase of the heating air temperature. The process must have been more intense and part of the energy must have been consumed by phase transition of evaporating water residues.

Table 2

\section{Statistical results of modelled effective thermal conductivity $\left(\lambda_{e f}\right)$ of willow pieces at various air temperatures}

\begin{tabular}{|c|c|c|c|c|}
\hline \multirow{2}{*}{ Parameter } & \multicolumn{4}{|c|}{ Temperature, $\mathbf{K}$} \\
\cline { 2 - 5 } & $\mathbf{3 1 3 . 1 5}$ & $\mathbf{3 2 3 . 1 5}$ & $\mathbf{3 3 3 . 1 5}$ & $\mathbf{3 4 3 . 1 5}$ \\
\hline $\boldsymbol{R M S E}$ & 0.0022 & 0.0033 & 0.0071 & 0.0136 \\
\hline $\boldsymbol{M A P E}$ & 6.2412 & 6.7135 & 11.0478 & 16.9599 \\
\hline $\boldsymbol{R}^{2}$ & 0.9633 & 0.9710 & 0.9549 & 0.91705 \\
\hline$\chi^{2}$ & 0.0009 & 0.0018 & 0.0061 & 0.0195 \\
\hline
\end{tabular}

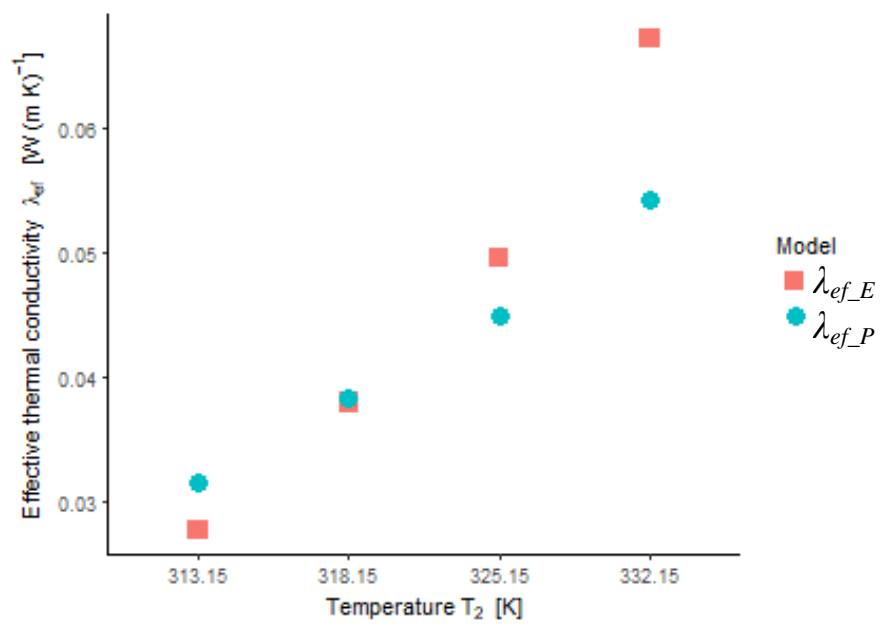

Fig. 5. Experimental and modelled effective thermal conductivity $\left(\lambda_{e f}\right)$ of willow versus temperature $\left(\boldsymbol{T}_{2}\right): \lambda_{e f_{-} E}-$ experimental results of thermal conductivity $\lambda_{e f}, \lambda_{e f-P}-$ modelled thermal conductivity $\lambda_{e f}$

\section{Conclusions}

1. It is found from the results of this experimental investigation that the heating air temperature has an important role on the effective thermal conductivity $\lambda_{\text {eff }}$. With the increase of the air heating temperature, the $\lambda_{\text {eff }}$ values rise as well.

2. The model is used to describe the effective thermal conductivity $\lambda_{\text {eff }}$ by means of porosity and density of the willow pieces yielding the high values of evaluation parameters for all air heating temperatures. The best values of $R^{2}$ and MAPE were obtained in the case of $323.15 \mathrm{~K}\left(50{ }^{\circ} \mathrm{C}\right)$.

3. Performed statistical analysis indicates that the predicted model is a good fit for the actual effective thermal conductivity data at modest air heating temperatures.

\section{Acknowledgements}

This work was supported by Higher Education in Poland, statutory activities DS3600/WIPiE/2018, Faculty of Production and Power Engineering, University of Agriculture in Krakow. 


\section{References}

[1] Kamke F.A., Zylkowski S.C,. Effects of Wood-based panel characteristics on thermal conductivity. Forest Prod. J. 1989, 39 (5), pp. 19-24.

[2] Wróbel M., Mudryk K., Jewiarz M., Głowacki S., Tulej W. (2018) Characterization of Selected Plant Species in Terms of Energetic Use. In: Mudryk K., Werle S. (eds) Renewable Energy Sources: Engineering, Technology, Innovation. Springer Proceedings in Energy. Springer, Cham pp. 671-681 doi.org/10.1007/978-3-319-72371-6_66.

[3] Bader H., Niemz P., Sonderegger W. Untersuchungen zum Einfluss des Plattenaufbaus auf ausgewählte Eigenschaften von Massivholzplatten (Investigations on the influence of panel construction on selected properties of solid wood panels). Holz Roh- Werkst, 2007, 65(3), pp. 173-181. (In German)

[4] Sonderegger W, Niemz P (2006) Untersuchungen zur Quellung und Wärmedehnung von Faser-, Span- und Sperrholzplatten (Investigations on swelling and thermal expansion of fiber, chip and plywood boards). Holz. Roh- Werkst., 2007, 64(1) , pp. 11-20. (In German)

[5] Cammerer J., Achtziger J. Einfluss des Feuchtegehaltes auf die Wärmeleitfähigkeit von Bau- und Dämmstoffen ()Influence of the moisture content on the thermal conductivity of construction and insulation materials. Bauforschungsbericht des Bundesministers f "ur Raumordnung, Bauwesen und Städtebau, Bonn, F 1988. IRB Verlag, Stuttgart, 1984. (In German)

[6] Bučar B., Straže A.. Determination of the thermal conductivity of wood by the hot plate method: the influence of morphological properties of fir wood (Abies alba Mill.) to the contact resistance. Holzforschung, 2008, 62, pp. 362-367.

[7] Asako Y., Kamikoga H., Nishimura H., Yamaguchi Y.. Effective thermal conductivity of compressed woods. Int. J. Heat Mass Transf., 2002, 45, pp. 2243-2253.

[8] Gobbé C., Iserna S., Ladevie B.. Hot strip method: application to thermal characterisation of orthotropic media. Int. J. Therm. Sci ., 2004, 43, pp. 951-958.

[9] Hammerschmidt U., Sabuga W.. Transient hot strip (THS) method: uncertainty assessment. Int J. Thermophys., 2000, 21, pp. 217-248.

[10] Czajkowski Ł., Olek W., Weres J. Guzenda R.. Thermal properties of Wood-based panels: thermal conductivity identyficationwith inverse model ling. EUR. J. Wood Prod., 2016, 74, 577 p. https://doi.org/10.1007/s0107-016-1021-6Kays W.M., London A.L., Compact Heat Exchangers ( $3^{\text {rd }}$ ed.). Malabar, FL: Krieger Publishing Company

[11] Weres J., Kujawa S., Olek W., Czajkowski W.. Integration of experimental and computational methods for identifying geometric, thermal and diffusive properties of biomaterials, Int. Agrophys., 2016, 30 p.

[12]Zhang N., Wang Z., Review of soil thermal conductivity and predictive models, International Journal of Thermal Sciences 117 (2017) 172, 183 p.

[13] Strumiłło, C. Podstawy teorii i techniki suszenia (Basics of drying theory and technique), Warszawa, Wyd. Nauk. -Techniczne, 1983. (In Polish)

[14] Ražnjević, K. Tablice cieplne z wykresami (Thermal tables with charts), Wyd. Nauk.-Techniczne, Warszawa, 1966. (In Polish)

[15] Adler J., R in nutshell, O’Reilly Media, Inc, 2010, ISBN: 978-0-596-80170-0 